\title{
In Situ Structural Characterization of Phosphatidylcholines in Brain Tissue Using MALDI-MS/MS
}

\author{
Shelley N. Jackson, Hay-Yan J. Wang, and Amina S. Woods \\ National Institute of Drug Abuse Intramural Research Program, National Institutes of Health, Baltimore, \\ Maryland, USA
}

\begin{abstract}
Phosphatidylcholine (PC) is one of the most abundant classes of phospholipids and is a major component of membranes in biological systems. Recently, PCs have been detected by direct tissue analysis using MALDI-TOFMS. However, these studies did not allow for the structural characterization of PCs in tissue. In the current study, an in situ method for detection and structural analysis of PC species in brain tissue was developed using a MALDI-TOF/TOF mass spectrometer. Initial profiling of lipids in tissue is performed by MALDI-TOFMS, which allows for the assignment of PC species. However, to confirm the structure of the PC species detected in tissue, MALDI-MS/MS analysis was employed. In this work, protonated, sodiated, and potassiated PC species were detected in brain tissue using DHA matrix. MALDI-MS/MS analysis of these species yielded fragments that verified a phosphocholine head group, but did not supply any fragments that would permit the identification of acyl substituents. To obtain more structural information, lithium adducts of PC species were produced using DHA matrix dissolved in $100 \mathrm{mM}$ lithium chloride. MALDI-MS/MS analysis of lithiated PC species produced fragments that allowed for the identification and positional assignment of acyl groups in PC species. (J Am Soc Mass Spectrom 2005, 16, 2052-2056) (C) 2005 American Society for Mass Spectrometry
\end{abstract}

$\mathrm{P}$ hosphatidylcholines (PC), a class of glycerophospholipids, are main building blocks of biological membranes accounting for $\sim 50 \%$ of phospholipid mass in cell membranes of eukaryotic cells [1,2]. PCs also play an important role in cell signaling [3], and the disruption of PC homeostasis in mammalian cell leads to cell death [4]. The basic structure of phosphatidylcholine (1,2-diacyl-sn-glycero-3-phosphocholine) is in Figure 1. PC consists of a phosphocholine head group and a glycerol backbone with two acyl (fatty acid) tails. The two acyl groups are attached to the glycerol backbone at the sn- 1 and sn- 2 position. The polar phosphocholine head group gives PC a strong zwitterionic character.

Several studies have employed matrix-assisted laser desorption/ionization mass spectrometry (MALDI-MS) for the detection and structural analysis of PCs [5-8]. Due to the presence of a positively charged quaternary amine, PC species are easily ionized in positive ion mode. Fragments observed in MALDI-MS spectra, corresponding to the loss of trimethylamine, phosphocholine head group, and acyl groups, have been used for structural characterization of PCs $[5,6] . \mathrm{MS}^{2}$ of PCs using MALDI-FTICR/MS have produced abundant

Published online October 25, 2005

Address reprint requests to Dr. A. S. Woods, National Institute on Drug Abuse Intramural Research Program, National Institutes of Health, Baltimore, MD 21224, USA. E-mail: awoods@intra.nida.nih.gov ions at $m / z=184$ attributed to the head group of PC [6]. Additionally, post-source decay (PSD) MALDI-MS has also been employed for the structural analysis of PCs [7]. In this study, sodiated PC species were analyzed with PSD coupled with MALDI-MS and produced fragments, corresponding to the loss of trimethylamine, phosphocholine head group, and acyl groups.

MALDI-MS methods have been developed for the in situ analysis of biomolecules, typically peptides and proteins, from tissue [9-11]. Due to its high sensitivity, tolerance for salts and other contaminants, and a wide mass range with little fragmentation, MALDI is the ionization method of choice for the direct analysis of complex samples such as tissue. In these methods, matrix is deposited directly onto a tissue section and then mass analyzed with no additional sample preparation. Direct tissue analysis using MALDI produces mass spectral profiles, which can be employed to map the location of molecules in tissue. Recently, MALDI-MS has been used for direct analysis of phospholipids in lens tissue [12] and in rat brain tissue [13, 14]. In these studies, positive ion MALDI mass spectra were dominated by PC species, which showed different regional distribution in the relative abundance of PC species in tissue.

In this work, in situ analysis of PCs in rat brain tissue was conducted using a MALDI-TOF/TOF mass spectrometer. Tandem MS analysis of protonated, sodiated, and potassiated PC species yielded fragments that 


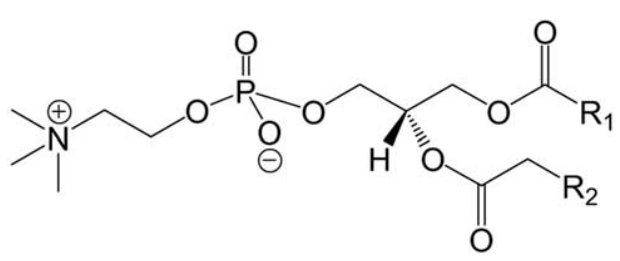

Figure 1. Phosphatidylcholine.

correspond to the loss of trimethylamine and the head group from PC and the phosphocholine molecular ion. To generate fragments with more pertinent structural information, lithiated PC species were analyzed. Lithium adducts were produced by using 2,6-dihydroxyacetophenone matrix dissolved in $100 \mathrm{mM}$ lithium chloride. Tandem MS analysis of lithiated PC species yielded fragment mass peaks that correspond to the loss of trimethylamine, the phosphocholine head group, and acyl groups.

\section{Experimental}

\section{Mass Spectrometer}

A MALDI-TOF/TOF (4700 Proteomics Analyzer, Applied Biosystems, Framingham, MA) was used in this study for both MS and MS/MS analyses and has been described in detail previously [15]. $.^{\circ} \mathrm{A}^{\circ} \mathrm{Nd}: \mathrm{YAG}^{\circ}$ laser $(355 \mathrm{~nm})$ at a repetition rate of $200 \mathrm{~Hz}$ was employed for ionization. For MS analysis, mass spectra were the sum of 400 laser shots and acquired in reflectron mode. For MS/MS analysis, mass spectra were the sum of 1000 laser shots, a collision energy of $1 \mathrm{keV}$ with air as the collision gas was used to induce fragmentation. The following lipid standards were used to calibrate the mass spectrometer: brain phosphatidylcholines (99\%, porcine, Avanti Polar Lipids, Alabaster, AL) and sphingomyelins (99\%, porcine, Avanti Polar Lipids).

\section{Tissue Sectioning}

All animal use and handling in this work abide by the Guide for the Care and Use of Laboratory Animals $(\mathrm{NIH})$. Male Sprague-Dawley rats (Harlan Industries, Indianapolis, IN) between 300 and $420 \mathrm{~g}$ were euthanized by an intraperitoneal injection of sodium pentobarbital $(>65 \mathrm{mg} / \mathrm{kg}$ ). The brains were quickly removed from the skull and frozen in dry ice-chilled isopentane for $15 \mathrm{~s}$, before storage at $-80^{\circ} \mathrm{C}$. Frozen brain tissue was cut into thin sections (14 $\mu \mathrm{m}$ thickness) in a cryostat (CM 3050 S; Leica Microsystems Nussloch $\mathrm{GmbH}$, Nussloch, Germany). Serial brain sections were alternately placed onto a MALDI sample target and poly-L-lysine coated microscopic slide. The tissue sections on the microscopic slides were stained with cresyl violet $^{\circ}$ and $^{\circ} \mathrm{a}^{\circ}$ rat $^{\circ}$ brain $^{\circ}$ atlas $^{\circ}[16]^{\circ}$ was $^{\circ}$ used $^{\circ}$ for ${ }^{\circ}$ the assignment of the brain region analyzed by mass spectrometry.

\section{Sample Preparation}

The MALDI matrix used in this study was 2,6-dihydroxyacetophenone, DHA, (Fluka, Buchs, Switzerland). Lithium chloride (Sigma-Aldrich, St. Louis, MO) was dissolved in $50 \%$ ethanol at a concentration of $100 \mathrm{mM}$. Matrix solutions were prepared in $50 \%$ ethanol or $100 \mathrm{mM}$ $\mathrm{LiCl}$ in $50 \%$ ethanol at a concentration of $30 \mathrm{mg} / \mathrm{mL}$ for DHA. For tissue analysis, $0.1 \mu \mathrm{L}$ of matrix solution was deposited directly on the section, resulting in a matrix spot size between 800 and $1500 \mu \mathrm{m}$, and allowed to air-dry before insertion into the mass spectrometer.

\section{Lipid Assignment}

In MALDI-TOF mass spectra, the PC species number equals the total length and number of double bonds of both acyl chains, while the SM species number corresponds to the length and number of double bonds of the acyl chain attached to the sphingosine base. Assignment of PC species based upon product-ion spectra is as follows: PC sn-1 acyl group/sn-2 acyl group.

\section{Results and Discussion}

Experiments were conducted analyzing PCs in situ from rat brain tissue with DHA matrix by MALDITOFMS $^{\circ}$ and ${ }^{\circ}$ MALDI-TOF/TOFMS. ${ }^{\circ}$ Figure ${ }^{\circ}{ }^{\circ}$ illustrates a typical mass spectrum of rat brain tissue with DHA matrix. This mass spectrum was obtained from the cerebral cortex region of the brain in positive ion reflectron mode. The most dominant mass peaks in Figure $^{\circ} 2^{\circ}$ assigned $^{\circ}$ to $^{\circ} \mathrm{PCs}^{\circ}$ were $^{\circ}$ the ${ }^{\circ}$ following ${ }^{\circ}$ two species: PC 32:0 and PC 34:1. The molecular ions, [M + $\mathrm{H}]^{+},[\mathrm{M}+\mathrm{Na}]^{+}$, and $[\mathrm{M}+\mathrm{K}]^{+}$, were detected for both species. Mass peaks associated with a sphingomyelin (SM) species, SM18:0, was also observed. These results are ${ }^{\circ}{ }^{\circ}$ good $^{\circ}$ agreement ${ }^{\circ}$ with $^{\circ} a^{\circ}$ previous ${ }^{\circ}$ study $^{\circ}[13]^{\circ}$ using MALDI-TOFMS for direct tissue analysis of the cerebral cortex region of rat brain.

To confirm the assignment of PC species, MALDIMS/MS analysis was conducted on the mass peaks

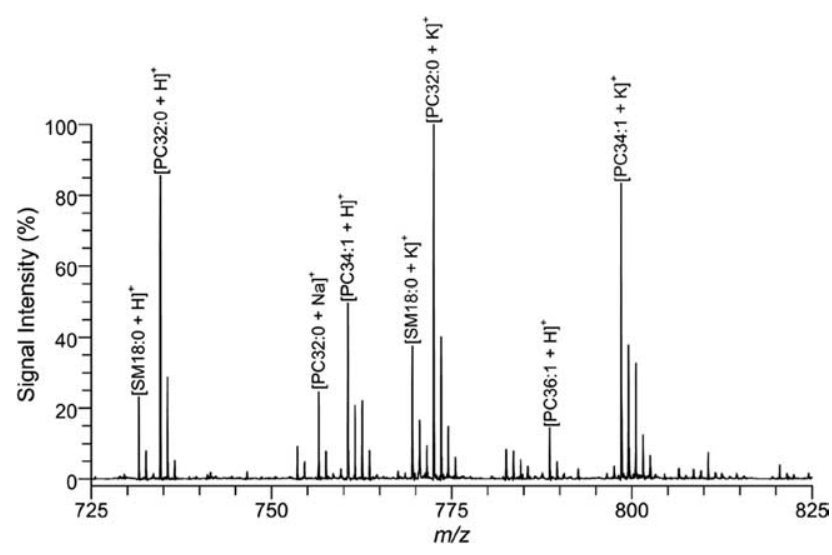

Figure 2. (a) MALDI mass spectrum of cerebrum cortex with DHA matrix. 
observed $^{\circ}$ in $^{\circ}$ Figure $^{\circ} 2 .^{\circ} \mathrm{A}^{\circ}$ product-ion $^{\circ}$ spectrum ${ }^{\circ}$ of ${ }^{\circ}[\mathrm{PC}$ $32: 0+\mathrm{H}]^{+}(\mathrm{m} / \mathrm{z}=734.585)$ in positive ion mode with DHA matrix contained only one major fragment peak observed at $m / z=184.072$. This mass peak corresponds to phosphocholine $\left(\mathrm{C}_{5} \mathrm{H}_{15} \mathrm{O}_{4} \mathrm{~N}\right)$, which is formed by the loss of the polar head group of PC. This result is in agreement with previous MS/MS studies using MALDI-FTICR/MS ${ }^{\circ}[6]^{\circ}{ }^{\circ}$ electrospray-MS ${ }^{\circ}$ (ESI-MS) ${ }^{\circ}[17-$ 19], ${ }^{\circ}{ }^{\circ}{ }^{\circ} \mathrm{PSD}^{\circ} \mathrm{MALDI}-\mathrm{MS}^{\circ}[7] .{ }^{\circ} \mathrm{MALDI}-\mathrm{MS} / \mathrm{MS}^{\circ}$ analysis of ${ }^{\circ}$ all ${ }^{\circ}$ other ${ }^{\circ}$ protonated ${ }^{\circ} \mathrm{PC}^{\circ}$ species ${ }^{\circ}{ }^{\circ}{ }^{\circ}$ Figure $2^{\circ}$ yielded $^{\circ} \mathrm{a}$ similar fragmentation pattern, in which the only major peak was phosphocholine.

Additional experiments were performed in which sodiated and potassiated PC species were analyzed by MALDI-TOF/TOF. A product-ion spectrum of [PC 32:0 $+\mathrm{K}]^{+}(\mathrm{m} / \mathrm{z}=772.524)$ consisted of fragment peaks at $\mathrm{m} / \mathrm{z}$ 713.491, 162.958, and 551.602. The mass peak at $713.491 \mathrm{Da}$ is produced by the neutral loss of trimethylamine $\left[\mathrm{N}\left(\mathrm{CH}_{3}\right)_{3}\right]$ from the parent ion, while the mass peak at $162.958 \mathrm{Da}$, corresponds to a potassiated fivemembered cyclophosphane ring $\left(\mathrm{C}_{2} \mathrm{H}_{5} \mathrm{O}_{4} \mathrm{P}+\mathrm{K}\right)$. The fragment peak at $\mathrm{m} / \mathrm{z}=551.602$ is assigned as [PC 32:0 $\left.-\mathrm{N}\left(\mathrm{CH}_{3}\right)_{3}-\mathrm{C}_{2} \mathrm{H}_{5} \mathrm{O}_{4} \mathrm{P}-\mathrm{K}+\mathrm{H}\right]^{+}$and attributed to the net loss of the phosphocholine head group and potassium from the parent ion. Further analysis of potassiated ${ }^{\circ}$ and $^{\circ}$ sodiated $^{\circ} \mathrm{PC}^{\circ}$ species $^{\circ}$ in $^{\circ}$ Figure $^{\circ} 2^{\circ}$ produced product-ion spectra with similar fragment peaks with the major difference being the substitution of sodium for potassium in sodiated PC species. Previous MS/MS studies ${ }^{\circ}$ of $^{\circ}$ sodiated ${ }^{\circ}$ species ${ }^{\circ}$ using ${ }^{\text {ESSI/MS }}$ [20], ${ }^{\prime}$ fast ${ }^{\circ}$ atom bombardment ${ }^{\circ}$ mass $^{\circ}$ spectrometry $^{\circ}(\text { FAB-MS })^{\circ}[21],{ }^{\circ}$ and PSD $^{\circ}$ MALDI-MS ${ }^{\circ}[7]^{\circ}$ have ${ }^{\circ}$ yielded ${ }^{\circ}$ similar ${ }^{\circ}$ fragment peaks. ${ }^{\circ}$ However, ${ }^{\circ}$ in $^{\circ}$ some $^{\circ}$ of ${ }^{\circ}$ these ${ }^{\circ}$ previous $^{\circ}$ studies ${ }^{\circ}[7$, 21 $]^{\circ}$ additional fragment ${ }^{\circ}$ peaks ${ }^{\circ}$ corresponding to the loss acyl groups were also observed. In our work, MALDIMS/MS analysis of sodiated and potassiated PC species did not produce any significant fragment peaks corresponding to the loss of acyl groups.

To gain more structural information on PC species by ${ }^{\circ}$ ESI-MS $/ \mathrm{MS}^{\circ}$ analysis, ${ }^{\circ}$ previous ${ }^{\circ}$ studies ${ }^{\circ}\left[17,{ }^{\circ} 18\right]^{\circ}$ have generated lithium adducts of PC species. In these previous works it was demonstrated that lithiated adducts of PC species were more extensively fragmented than protonated PC species; thus yielding more pertinent structural information, allowing for the assignment of acyl groups. In the current work, the matrix, DHA, was dissolved in $100 \mathrm{mM} \mathrm{LiCL}$ and deposited directly onto the ${ }^{\circ}$ tissue ${ }^{\circ}$ sections $^{\circ}$ to $^{\circ}$ produce $^{\circ}$ lithium ${ }^{\circ}$ adducts. ${ }^{\circ}$ Figure $3 a^{\circ}$ illustrates ${ }^{\circ} \mathrm{a}^{\circ}$ typical ${ }^{\circ} \mathrm{MALDI}-\mathrm{TOF}^{\circ}$ mass $^{\circ}$ spectrum $^{\circ}$ of rat brain tissue with $\mathrm{DHA} / \mathrm{LiCl}$ matrix. This mass spectrum was obtained from the cerebral cortex region of the brain in positive ion reflectron mode. The two major peaks in this mass spectrum are the lithium adducts ${ }^{\circ}$ of ${ }^{\circ} \mathrm{PC}^{\circ} 32: 0^{\circ}$ and ${ }^{\circ} \mathrm{PC}^{\circ} 34: 1 .{ }^{\circ}$ Figure ${ }^{\circ} 3 \mathrm{a}^{\circ}$ is ${ }^{\circ}$ in ${ }^{\circ}$ agreement $^{\circ}$ with $^{\circ}$ Figure $^{\circ} 2 a^{\circ}{ }^{\circ}$ in $^{\circ}$ which ${ }^{\circ}$ the ${ }^{\circ}$ same $^{\circ}$ major ${ }^{\circ} \mathrm{PC}$ species are observed except that they are lithium adducts.

Figure $3 \mathrm{~b}^{\circ}$ shows $^{\circ} \mathrm{a}^{\circ}$ product-ion ${ }^{\circ}$ spectrum ${ }^{\circ}$ of ${ }^{\circ}\left[\mathrm{PC}^{\circ} 32: 0\right.$ $+\mathrm{Li}^{+}(\mathrm{m} / \mathrm{z}=740.514)$ in positive ion mode with
DHA/LiCl matrix. Several fragment peaks providing structural information are recorded. The mass peak at $\mathrm{m} / \mathrm{z}=681.536$ corresponds to the neutral loss of trimethylamine while the mass peaks at $557.560[\mathrm{M}+\mathrm{Li}-$ $\left.\mathrm{N}\left(\mathrm{CH}_{3}\right)_{3}-\mathrm{C}_{2} \mathrm{H}_{5} \mathrm{O}_{4} \mathrm{P}\right]^{+}$and $551.516 \mathrm{Da}[\mathrm{M}+\mathrm{H}-$ $\left.\mathrm{N}\left(\mathrm{CH}_{3}\right)_{3}-\mathrm{C}_{2} \mathrm{H}_{5} \mathrm{O}_{4} \mathrm{P}\right]^{+}$, correspond to the net loss of the phosphocholine head group with and without lithium. Structural information enabling the identification of the acyl groups of the PC specie is provided by the mass peaks at $484.349,478.320$, and $425.311 \mathrm{Da}$. These mass peaks are attributed to losses of palmitic acid, the lithium salt of palmitate, and trimethylamine with palmitic acid as neutral molecules and are assigned as follows: $484.349\left[\mathrm{M}+\mathrm{Li}-\mathrm{C}_{16} \mathrm{H}_{32} \mathrm{O}_{2}\right]^{+}, 478.320[\mathrm{M}+\mathrm{H}$
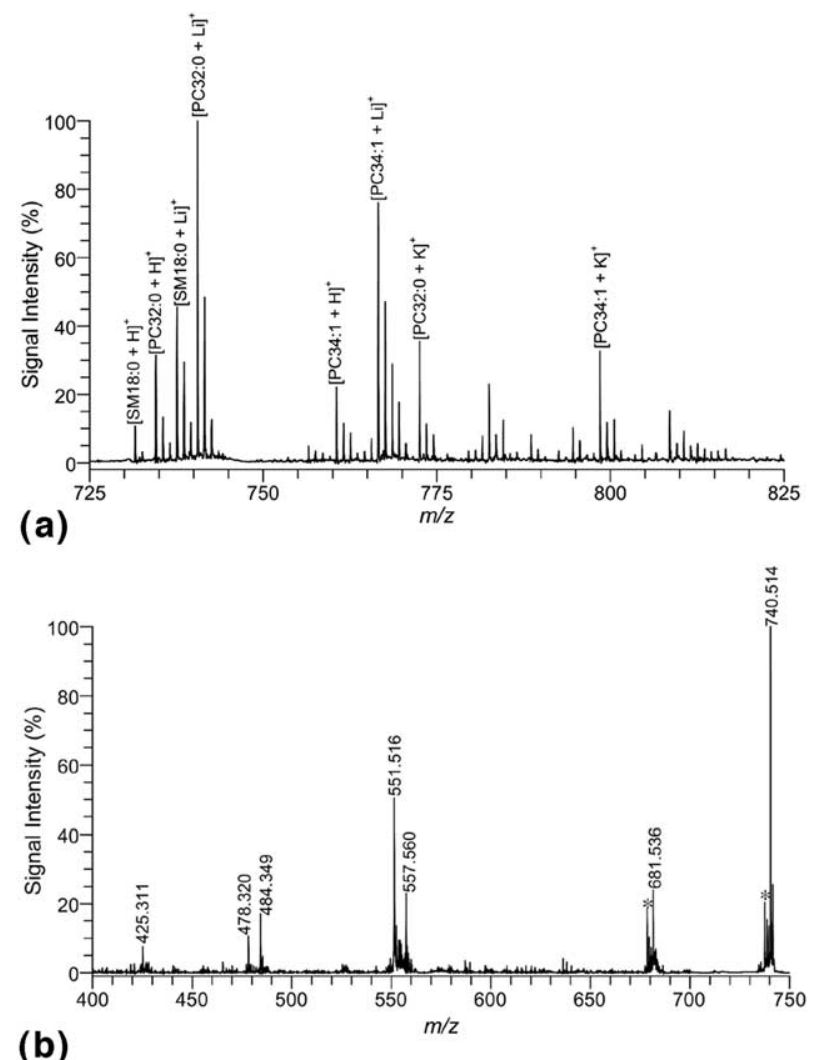

(b)

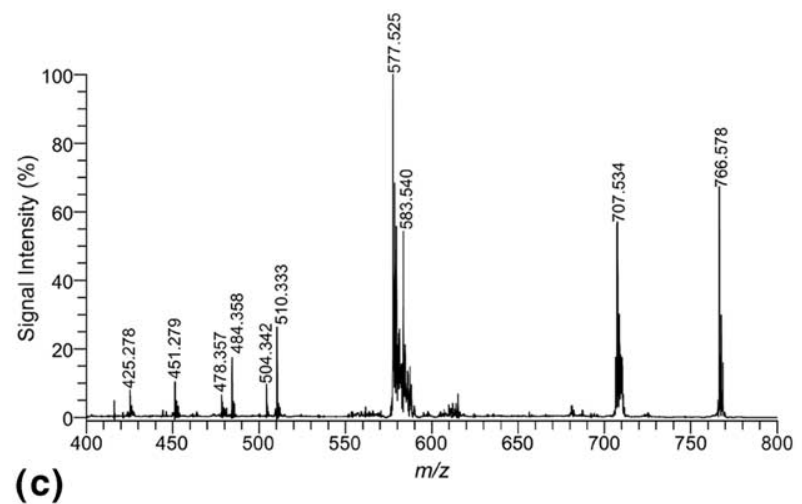

Figure 3. (a) MALDI mass spectrum of cerebrum cortex with DHA matrix in $100 \mathrm{mM} \mathrm{LiCL}$. MALDI/TOF-TOF mass spectra of (b) PC32:0+Li mass peak and (c) PC34:1+Li mass peak. 
$\left.-\mathrm{C}_{16} \mathrm{H}_{32} \mathrm{O}_{2}\right]^{+}, 425.311\left[\mathrm{M}+\mathrm{Li}-\mathrm{N}\left(\mathrm{CH}_{3}\right)_{3}-\right.$ $\left.\mathrm{C}_{16} \mathrm{H}_{32} \mathrm{O}_{2}\right]^{+}$. Based upon the fragment peaks observed in $^{\circ}$ Figure ${ }^{\circ} 3 b$, ${ }^{\circ}$ the ${ }^{\circ}$ major $^{\circ} \mathrm{PC}^{\circ}$ species ${ }^{\circ}$ contributing ${ }^{\circ}$ to ${ }^{\circ}$ the mass ${ }^{\circ}$ peak ${ }^{\circ}$ assigned ${ }^{\circ}$ as $^{\circ}\left[\mathrm{PC}^{\circ} 32: 0^{\circ}+{ }^{\circ} \mathrm{Li}\right]^{+}{ }^{\circ}$ in ${ }^{\circ} \mathrm{Figure}^{\circ} 3 \mathrm{a}^{\circ}$ is PC 16:0/16:0. The fragment peaks observed for lithiated PC species in tissue by MALDI-TOF/TOF analysis are in $^{\circ}$ similar $^{\circ}$ agreement ${ }^{\circ}$ with $^{\circ}{ }^{\circ S I-M S} /$ MS $^{\circ}$ studies $^{\circ}\left[17,{ }^{\circ} 18\right]$ of lithiated PC species.

One $^{\circ}$ additional ${ }^{\circ}$ note ${ }^{\circ}$ for $^{\circ}$ Figure $^{\circ} 3 b^{\circ}$ is ${ }^{\circ}$ the ${ }^{\circ}$ presence ${ }^{\circ}$ of interfering peaks corresponding to a sphingomyelin

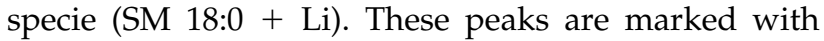
asterisks ${ }^{\circ}{ }^{\circ}{ }^{\circ}$ igure $3 b^{\circ}$ and ${ }^{\circ}$ were ${ }^{\circ}$ recorded ${ }^{\circ}$ at $737.565^{\circ}$ and $678.539 \mathrm{Da}$. These mass peaks are assigned as follows: $737.565\left[\mathrm{SM}\right.$ 18:0 + Li] ${ }^{+}, 678.539[\mathrm{SM}$ 18:0 $+\mathrm{Li}-$ $\left.\mathrm{N}\left(\mathrm{CH}_{3}\right)_{3}\right]^{+}$. This emphasizes the care that has to be taken in assigning mass peaks with direct tissue analysis in which several lipid species are present and can overlap in the same mass selection range.

Figure $3 c^{\circ}$ is ${ }^{\circ}$ a product-ion ${ }^{\circ}$ spectrum ${ }^{\circ}$ of $\left[\mathrm{PC} 34: 1^{\circ}+{ }^{\circ} \mathrm{Li}\right]^{+}$ $(\mathrm{m} / \mathrm{z}=766.578)$ in positive ion mode with $\mathrm{DHA} / \mathrm{LiCl}$ matrix. The major fragment peaks in this mass spectrum correspond to the neutral loss of trimethylamine (707.534 Da) and the net loss of the phosphocholine head group with and without lithium $\left(583.540\left[\mathrm{M}+\mathrm{Li}-\mathrm{N}\left(\mathrm{CH}_{3}\right)_{3}-\right.\right.$ $\left.\mathrm{C}_{2} \mathrm{H}_{5} \mathrm{O}_{4} \mathrm{P}\right]^{+}$and 577.525 Da $\left[\mathrm{M}+\mathrm{H}-\mathrm{N}\left(\mathrm{CH}_{3}\right)_{3}-\right.$ $\left.\mathrm{C}_{2} \mathrm{H}_{5} \mathrm{O}_{4} \mathrm{P}\right]^{+}$). Several additional fragment peaks were observed corresponding to the neutral losses of acyl groups and trimethylamine. The mass peaks were assigned as follows: $510.33\left[\mathrm{M}+\mathrm{Li}-\mathrm{C}_{16} \mathrm{H}_{32} \mathrm{O}_{2}\right]^{+}$loss of palmitic acid, $504.342\left[\mathrm{M}+\mathrm{H}-\mathrm{C}_{16} \mathrm{H}_{32} \mathrm{O}_{2}\right]^{+}$loss of the lithium salt of palmitate, $451.279\left[\mathrm{M}+\mathrm{Li}-\mathrm{N}\left(\mathrm{CH}_{3}\right)_{3}-\mathrm{C}_{16} \mathrm{H}_{32} \mathrm{O}_{2}\right]^{+}$ loss of trimethylamine and palmitic acid, $484.358[\mathrm{M}+\mathrm{Li}$ - $\left.\mathrm{C}_{18} \mathrm{H}_{34} \mathrm{O}_{2}\right]^{+}$loss of oleic acid, 478.357 [M + H $\left.\mathrm{C}_{16} \mathrm{H}_{32} \mathrm{O}_{2}\right]^{+}$loss of the lithium salt of oleate, $425.278[\mathrm{M}+$ $\left.\mathrm{Li}-\mathrm{N}\left(\mathrm{CH}_{3}\right)_{3}-\mathrm{C}_{18} \mathrm{H}_{34} \mathrm{O}_{2}\right]^{+}$loss of trimethylamine and oleic acid. Based upon the fragment peaks observed in Figure ${ }^{\circ} 3 \mathrm{c}^{\circ}$, the ${ }^{\circ}$ major ${ }^{\circ} \mathrm{PC}^{\circ}$ specie ${ }^{\circ}$ contributing ${ }^{\circ}$ to ${ }^{\circ}$ the ${ }^{\circ}$ mass peak $^{\circ}$ assigned ${ }^{\circ}$ as $^{\circ}\left[\mathrm{PC}^{\circ} 34: 1^{\circ}+{ }^{\circ} \mathrm{Li}^{+{ }^{\circ}}{ }^{\circ}\right.$ in $^{\circ}$ Figure $^{\circ} 3 \mathrm{a}^{\circ}$ is ${ }^{\circ} \mathrm{PC}$ 16:0/18:1. The positional assignment of acyl groups accordingly as sn-1or sn-2 substituents is based upon previous $^{\circ}$ fragmentation ${ }^{\circ}$ studies ${ }^{\circ}\left[7,{ }^{\circ} 17\right]^{\circ}$ of $^{\circ} \mathrm{PC}^{\circ}$ species ${ }^{\circ}$ in ${ }^{\circ}$ which the abundance of ions corresponding to the loss of the sn-1 substituent is greater than the abundance of ions reflecting the loss of the sn-2 substituent. Previous studies of the distribution of PC species in rat brain have identified PC 16:0/18:1 as one of the most abundant PC species, which further supports are assignment based upon direct tissue analysis ${ }^{\circ} y^{\circ} \mathrm{MALDI}-\mathrm{TOF} / \mathrm{TOF}^{\circ}\left[22,{ }^{\circ 2} 3\right]$.

\section{Conclusions}

In this work, a method for in situ detection and structural analysis of PC species in brain tissue was developed using a MALDI-TOF/TOF mass spectrometer. Initial profiling of lipids in tissue is conducted by MALDI-TOFMS and allows for the assignment of PC species. To confirm the structure, lithium adducts of PC species were analyzed by MALDI-MS/MS and yielded fragments that allowed for the identification and posi- tional assignment of acyl groups in PC species. Future studies will include analyzing additional anatomical regions in rat brain tissue and other organs for PC distribution. Additional studies using MALDI-MS/MS will be conducted for the identification of other classes of phospholipids and gangliosides by direct tissue analysis.

\section{Acknowledgments}

This research was supported by the Intramural Research Program of the National Institute on Drug Abuse, NIH. The authors thank the Office of National Drug Control Policy (ONDCP) for instruments funding, without which this and other projects could not have been accomplished.

\section{References}

1. Hanahan, D. J. A Guide to Phospholipid Chemistry; Oxford University Press: New York, 1997; pp 65-74

2. Wright, M. M.; Howe, A. G.; Zaremberg, V. Cell Membranes and Apoptosis: Role of Cardiolipin, Phosphatidylcholine, and Anticancer Lipid Analogs. Biochem. Cell Biol. 2004, 82, 18-26.

3. Martelli, A. M.; Fala, F.; Faenza, I.; Billi, A. M.; Cappellini, A.; Manzoli, L.; Cocco, L. Metabolism and Signaling Activities of Nuclear Lipids. Cell. Mol. Life Sci. 2004, 61, 1143-1156.

4. Cui, Z.; Houweling, M. Phosphatidylcholine and Cell Death. Biochim. Biophys. Acta 2002, 87, 1585-96.

5. Harvey, D. J. Matrix-Assisted Laser Desorption/Ionization Mass Spectrometry of Phospholipids. J. Mass Spectrom. 1995, 30, 1333-1346.

6. Marto, J. A.; White, F. M.; Seldomridge, S.; Marshall, A. G. Structural Characterization of Phospholipids by MatrixAssisted Laser Desorption/Ionization Fourier Transform Ion Cyclotron Resonance Mass Spectrometry. Anal. Chem. 1995, 67, 3979-3984.

7. Al-Saad, K. A.; Siems, W. F.; Hill, H. H.; Zabrouskov, V.; Knowles, N. R. Structural Analysis of Phosphatidylcholines by Post-Source Decay Matrix-Assisted Laser Desorption/Ionization Time-of-Flight Mass Spectrometry. J. Am. Soc. Mass Spectrom. 2003, 14, 373-382.

8. Schiller, J.; Sub, R.; Arnhold, J.; Fuchs, B.; LeBig, J.; Muller, M.; Petkovic, M.; Spalteholz, H.; Zschornig, O.; Arnold, K. MatrixAssisted Laser Desorption and Ionization Time-of-Flight (MALDI-TOF) Mass Spectrometry in Lipid and Phospholipid Research. Prog. Lipid Res. 2004, 43, 449-488.

9. Schwartz, S. A.; Reyzer, M. L.; Caprioli, R. M. Direct Tissue Analysis Using Matrix-Assisted Laser Desorption/Ionization Mass Spectrometry: Practical Aspects of Sample Preparation. J. Mass Spectrom. 2003, 38, 699-708.

10. Chaurand, P.; Caprioli, R. M. Direct Profiling and Imaging of Peptides and Proteins from Mammalian Cells and Tissue Sections by Mass Spectrometry. Electrophoresis 2002, 23, 3125-3135.

11. Todd, P. J.; Schaaff, T. G.; Chaurand, P.; Caprioli, R. M. Organic Ion Imaging of Biological Tissue with Secondary Ion Mass Spectrometry and Matrix-Assisted Laser Desorption/ Ionization. J. Mass Spectrom. 2001, 36, 355-369.

12. Rujoi, M.; Estrada, R.; Yappert, M. C. In Situ MALDI-TOF MS Regional Analysis of Neutral Phospholipids in Lens Tissue. Anal. Chem. 2004, 76, 1657-1663.

13. Jackson, S. N.; Wang, H-Y. J.; Woods, A. S.; Ugarov, M.; Egan, T.; Schultz, J. A. Direct Tissue Analysis of Phospholipids in Rat Brain Using MALDI-TOFMS and MALDI-Ion MobilityTOFMS. J. Am. Soc. Mass Spectrom. 2005, 16, 133-138. 
14. Jackson, S. N.; Wang, H.-Y. J.; Woods, A. S. Direct Profiling of Lipid Distribution in Brain Tisuue Using MALDI-TOFMS. Anal. Chem. 2005, 77, 4523-4527.

15. Yergey, A. L.; Coorssen, J. R.; Backlund, P. S. Jr.; Blank, P. S.; Humphrey, G. A.; Zimmerberg, J.; Campbell, J. M.; Vestal, M. L. De Novo Sequencing of Peptides Using MALDI/TOF-TOF. J. Am. Soc. Mass Spectrom. 2002, 13, 784-791.

16. Paxinos, G.; Watson, C. The Rat Brain in Stereotaxic Coordinates, 3rd ed.; Academic Press: San Diego, 1997.

17. Hsu, F.-F.; Bohrer, A.; Turk, J. Formation of Lithiated Adducts of Glycerophosphocholine Lipids Facilitates Their Identification by Electrospray Ionization Tandem Mass Spectrometry. J. Am. Soc. Mass Spectrom. 1998, 9, 516-526.

18. Hsu, F.-F.; Turk, J. Electrospray Ionization/Tandem Quadrupole Mass Spectrometric Studies on Phosphatidylcholines: The Fragmentation Processes. J. Am. Soc. Mass Spectrom. 2003, 14, 352-363.

19. Pulfer, M.; Murphy, R. C. Electrospray Mass Spectrometry of Phospholipids. Mass Spectrom. Rev. 2003, 22, 332-364.
20. Han, X.; Gross, R. W. Structural Determination of Picomole Amounts of Phospholipids via Electrospray Ionization Tandem Mass Spectrometry. J. Am. Soc. Mass Spectrom. 1995, 6, 1202-1210.

21. Domingues, P.; Domingues, M. R. M.; Amado, F. M. L.; Ferrer-Correia, A. J. Characterization of Sodiated Glycerol Phosphatidylcholine Phospholipids by Mass Spectrometry. Rapid Commun. Mass Spectrom. 2001, 15, 799-804.

22. Agranoff, B. W.; Benjamins, J. A.; Hajra, A. K. In Basic Neurochemistry Molecular, Cellular, and Medical Aspects, 6th ed; Siegel, G. J.; Agranoff, B. W.; Albers, R. W.; Fisher, S. K.; Uhler, M. D.; Eds. Lippincott Williams and Wilkins: Philadelphia, 1999, pp. 47-67.

23. Ma, Y.-C.; Kim, H.-Y. Development of the On-Line HighPerformance Liquid Chromatography/Thermospray Mass Spectrometry Method for the Analysis of Phospholipid Molecular Species in Rat Brain. Anal. Biochem. 1995, 226, 293-301. 